\title{
Relationship between parental lung function and their children's lung function early in life
}

\author{
N. van Putte-Katier*, M. Koopmans*, C.S.P.M. Uiterwaal*,\#, B.M. de Jong*, \\ J.L.L. Kimpen", T.J.M. Verheij ${ }^{\#}$, M.E. Numans" and C.K. van der Ent*, on behalf of the \\ WHISTLER study group
}

ABSTRACT: This study investigated the relationship between parental lung function and their children's lung function measured early in life.

Infants were participants in the Wheezing Illnesses Study Leidsche Rijn (WHISTLER). Lung function was measured before the age of 2 months using the single occlusion technique. Parental data on lung function (spirometry), medical history and environmental factors were obtained from the linked database of the Utrecht Health Project.

Parental data on pulmonary function and covariates were available in $\mathbf{5 4 6}$ infants. Univariate linear regression analysis demonstrated a significant positive relationship between the infant's respiratory compliance and parental forced expiratory flow at $25-75 \%$ of forced vital capacity (FEF25-75\%), forced expiratory volume in $1 \mathrm{~s}$ (FEV1) and forced vital capacity. A significant negative relationship was found between the infant's respiratory resistance and parental FEF $25-75 \%$ and FEV1. No significant relationship was found between the infant's respiratory time constant and parental lung function. Adjusting for body size partially reduced the significance of the observed relationship; adjusting for shared environmental factors did not change the observed results.

Parental lung function levels are predictors of the respiratory mechanics of their newborn infants, which can only partially be explained by familial aggregation of body size. This suggests genetic mechanisms in familial aggregation of lung function, which are already detectable early in life.

KEYWORDS: Birth cohort, familial aggregation, heritability, infant, lung function

A few studies have demonstrated that parameters of lung function measured early in life are predictive for respiratory symptoms and outcome early in childhood [1]. In addition, there are many data showing a genetic trait in wheezing illnesses in childhood with a dominant maternal influence [2, 3], but it is not known whether familial small airways play a role in the inheritance of wheezing illnesses. Investigations in diverse populations have demonstrated familial aggregation of lung function at older ages [4-6], but whether the similarities of various pulmonary function testing variables are related to common familial environmental exposures or shared genes remains unclear. Several studies have shown a lack of major genetic effects on forced expiratory volume in $1 \mathrm{~s}$ (FEV1) in general populations [7-9], whereas others suggest important genetic effects [10-12]. Moreover, CHEN et al. [7] illustrated that different pulmonary function indices may have different mechanisms underlying the familial aggregation, e.g. the familial aggregation for FEV1 is most probably controlled by multiple loci with no major gene effect and caused by shared environmental factors, whereas for forced vital capacity (FVC), major genetic mechanisms are suggested [7, 13].

Whether parental lung function levels are related to early-life lung function in their children, or which other factors, such as age, body size and medical history of parents (asthma or allergy), as well as shared environmental factors during pregnancy and shortly after birth, play a role has not been reported. In addition, it would be interesting to investigate whether there is a dominant maternal or paternal influence for early-life lung function of children.

The aim of this study was to investigate, in the Wheezing Illnesses Study Leidsche Rijn (WHISTLER) cohort, whether parental lung function is related to early-life lung function of their children and which other factors, such as age, body size, medical history of parents, and
AFFILIATIONS

Depts of *Paediatric Pulmonology and

"Paediatric Infectious Disease, and \# Julius Center for Health Sciences and Primary Care, University Medical Centre Utrecht, Utrecht, The Netherlands.

CORRESPONDENCE

N. van Putte-Katier Dept of Paediatric Pulmonology University Medical Centre Utrecht Internal Postal Code KH 01.419.0 P.0. Box 85090 3508 AB Utrecht The Netherlands E-mail: nkatier@yahoo.com

Received:

March 032010

Accepted after revision:

Nov 102010

First published online:

Jan 132011 
shared environmental factors during pregnancy and shortly after birth, play a role in this relationship.

\section{METHODS}

\section{Study population}

All infants in the present study were participants in the WHISTLER study, a prospective, population-based birth cohort study of determinants of wheezing illnesses, including early-life lung function. The study design and rationale of the WHISTLER study have been described in detail previously [14]. Briefly, healthy infants born in Leidsche Rijn, a new residential area under construction near the city of Utrecht (the Netherlands), were invited by telephone to participate in this study before the age of 2 months. Exclusion criteria were gestational age $<36$ weeks, major congenital abnormalities and neonatal respiratory disease. A questionnaire completed by one parent was used to gather information on gestational age, birth weight and length, and exposure to tobacco smoke (active and passive maternal smoking during pregnancy and passive smoking of the child after birth). Lung function, weight and length were measured at inclusion. The paediatric medical ethics committee of the University Medical Center Utrecht approved the study. Written informed consent was obtained from the parents.

Parental data on medical history, lung function, anthropometrics and environmental factors (smoking status, exposure to pets and socioeconomic status) were obtained from the linked database of the Utrecht Health Project (LRGP; Leidsche Rijn Gezondheids Project), a large health monitoring study in Leidsche Rijn, which aimed to generate data for all inhabitants on determinants of health and disease, as previously described $[14,15]$. The medical ethics committee of the University Medical Center Utrecht approved the study. Written informed consent was obtained from all participants.

\section{Lung function tests}

Infant lung function was measured before the age of 2 months. Measurements were performed during natural sleep without the use of sedation. Data collection was confined to consecutive periods of quiet sleep in which posture was stable and respiration was regular. Lung function was assessed from measurement of passive respiratory mechanics (resistance (Rrs), compliance $(\mathrm{Crs})$ and time constant ( $\left.\tau_{\mathrm{rs}}\right)$ of the respiratory system) using the single occlusion technique (SOT) [16]. Airflow was measured using a heated Lilly-type pneumotachometer series 8300 (Hans Rudolph Inc., Kansas City, MO, USA; dead space $1.66 \mathrm{~mL}$, resistance $0.4 \mathrm{cmH}_{2} \mathrm{O}$ at $5 \mathrm{~L} \cdot \mathrm{min}^{-1}$ ) attached to a face mask (infant mask; Hans Rudolph Inc.). The mask was sealed to the infant's face using therapeutic silicone putty (Magic Putty; Oldelft Benelux BV, Delft, the Netherlands) to prevent air leaks and minimise dead space. Pressure changes at the airway opening were measured with a pressure transducer (type 163PC01D75; Honeywell International Inc., Morristown, NJ, USA). Volume was measured by electronic integration of the airflow signal. Flow, volume and pressure were digitised with a sampling rate of $200 \mathrm{~Hz}$, and interfaced to a computer for realtime display, storage and analysis. Before each measurement, calibration of flow and volume signals was performed using a $100-\mathrm{mL}$ precision syringe (Viasys Health, Höchberg, Germany). The pressure transducer was calibrated over the expected range using a pressure transducer tester (VeriCal ${ }^{\mathrm{TM}}$; Utah Medical
Products Inc., Midvale, UT, USA). To be considered acceptable, each occlusion was required to meet the criteria of the European Respiratory Society (ERS)/American Thoracic Society (ATS) Task Force on Infant Lung Function [17]. At least three technically acceptable occlusions were used to calculate mean $C_{r s}, R r s$ and $\tau_{r s}$ values. Lung function data were calculated offline using a custom software package (Luna 1.7, Utrecht, the Netherlands).

Parental lung function was evaluated with a Vitalograph 2120 (Vitalograph Ltd, Buckingham, UK). At least three forced expirations were performed in accordance with the guidelines of the ATS [18]. A maximum of the three measurements was used. The lung function variables used in the analysis were: forced expiratory flow at $25-75 \%$ of FVC (FEF25-75\%), FEV1 and FVC. The FEF $25-75 \% / F V C$ ratio was calculated, which is a relatively size-independent measure of airway calibre [19].

\section{Definition of variables}

The role of factors, such as age, body size, medical history of parents, and shared environmental factors during pregnancy and shortly after birth (smoking status of parents, exposure to pets and socioeconomic status), in the relationship to lung function of parents and their children was examined. A positive history of asthma or bronchitis was defined as the parents having been diagnosed with asthma or bronchitis in the previous 12 months. A positive history of allergy included allergy to pollen, house dust mite, pets, drugs or food. Based on the Utrecht Health Project questionnaire, parents were divided into three smoking categories (never-, ex- and current smoker). Based on the WHISTLER questionnaire, three additional smoking variables were available (active and passive maternal smoking during pregnancy and passive smoking of the child after birth). Socioeconomic status was based on educational level and defined as low (no formal education, lower secondary education or intermediate secondary education), middle (higher secondary education) or high (higher vocational or university education). Ethnic origin was classified as Caucasian versus nonCaucasian.

\section{Statistical analysis}

Prior to modelling, all variables were checked for normality of distribution and, when necessary, logarithmic transformations were applied. Z-scores for parental lung function variables, height and weight were calculated. Linear regression analysis was used to examine the relationship between parental lung function variables (sum of absolute values of paternal and maternal FEF25-75\%, FEV1, FVC, and sum of FEF25-75\%/FVC) and their children's Rrs, $C_{r s}$ and $\tau$ rs. Univariate regression models were constructed with lung function variables of the children as dependent (outcome) variables, and the sum of maternal and paternal lung function variables as the independent variables (model I). Subsequently, five multiple linear regression models were constructed to investigate the influence of age, gestational age and sex (model II), body size of the infant at the time of visit for lung function measurement (model III) and at birth (model IV), body size of parents (model V), and exposure to pets, parental socioeconomic status, parental smoking status, and parental asthma and allergy status (model VI). To further investigate the role of infant body size (weight at the time of measurement) specific $\mathrm{Crs}$ ( $\mathrm{Crs}$ per $\mathrm{kg}$ ) and specific 


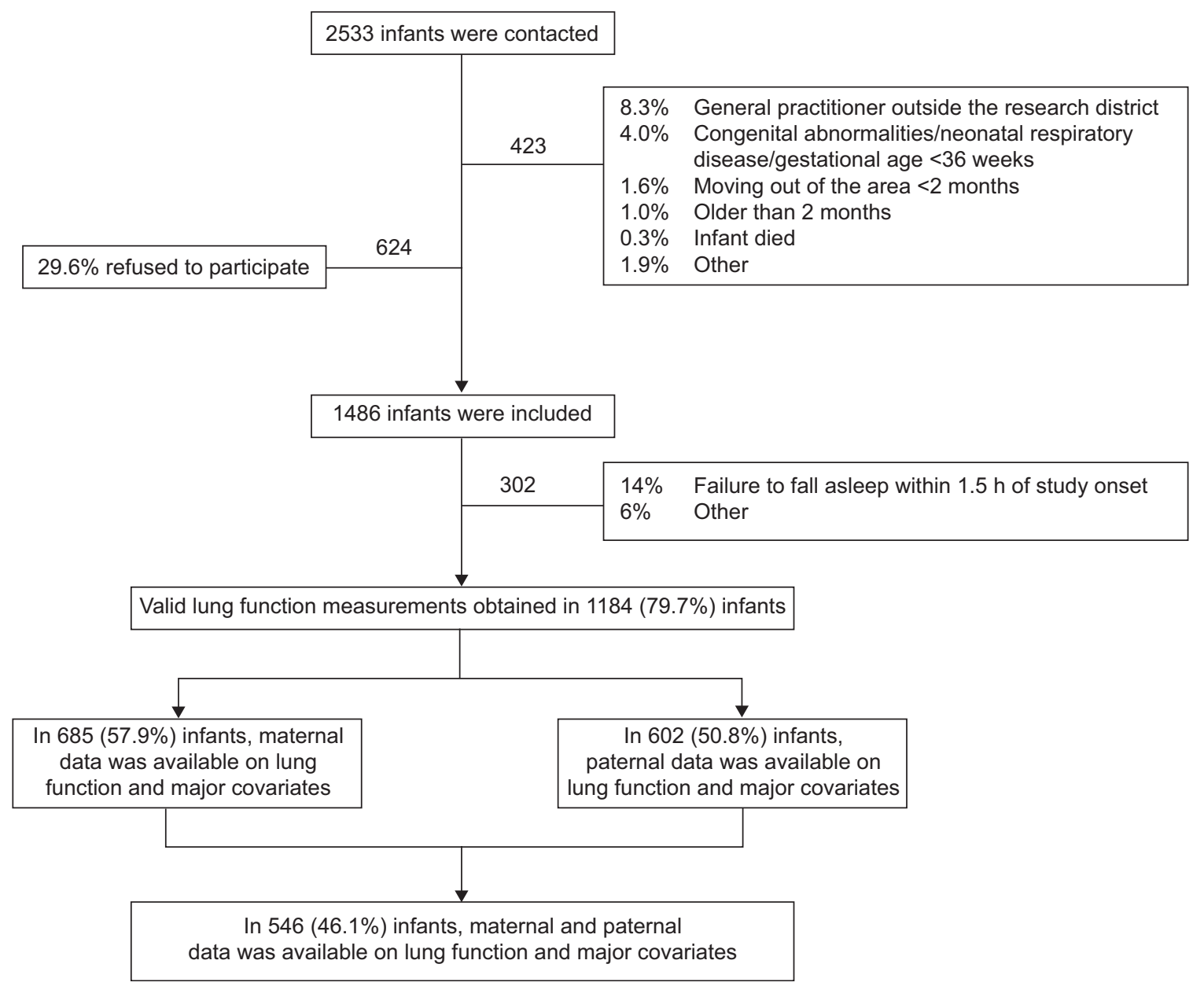

FIGURE 1. Overview of the inclusion of infants.

$\operatorname{Rrs}(R \mathrm{rs}$ per $\mathrm{kg}$ ) were used as dependent (outcome) variables in the last model (model VII). Analyses were repeated for maternal and paternal lung function variables separately. Normality of residuals distribution was checked to assess the fit of the models. Results are presented as linear regression coefficients and $95 \%$ confidence intervals. Intervals not including zero ( $p$ value $\leqslant 0.05$ ) were considered statistically significant. Statistical analysis was performed using SPSS for Windows, version 15.0 (SPSS Inc., Chicago, IL, USA).

\section{RESULTS}

\section{Demographic and clinical characteristics of parents and their children}

Figure 1 shows an overview of recruitment and inclusion of infants in the WHISTLER study. Among the 1,486 infants included, valid lung function measurements were obtained in $1,184(79.7 \%)$ infants. Failure to obtain technically acceptable measurements was mainly due to failure to fall asleep naturally within $1.5 \mathrm{~h}$ of study onset $(14 \%)$. Of the infants with successful lung function, maternal data on pulmonary function and major covariates could be derived from the linked database of the Utrecht Health Project in 685 (57.9\%) cases (352 female infants) and paternal data in 602 (50.8\%) cases (313 female infants). Both maternal and paternal data on pulmonary function and major covariates were available in $546(46.1 \%)$ infants. The mean and standard deviation of age, height, weight, levels of lung function, and the frequency distribution of educational level, smoking status, exposure to pets and allergy and asthma status of the parents and their newborn infant are shown in tables 1 and 2, respectively. Fathers had significantly larger values for all lung function variables, height and weight, and there was a 2-yr age difference between fathers and mothers. Among fathers, there were more current smokers and education was lower compared with the mothers. Male children had a significantly higher birth weight and length, and weight and length at the time of lung function measurement compared with female children.

\section{Lung function of parents and their children}

Table 3 shows the results of the univariate linear regression analysis with the sum of parental lung function variables as the independent variables and their children's lung function variables as the dependent (outcome) variables (model I). A significant positive relationship between $C_{r s}$ of the infant and parental FEF25-75\%, FEV1 and FVC was found. A significant negative relationship between $R$ rs of the infant and parental FEF25-75\% and FEV1 was found. The relationship between $R r s$ and FEF25-75\%/FVC was borderline significant. No significant relationship was found between $\tau_{\mathrm{rs}}$ of the infant and parental lung function variables. Figures 2, 3 and 4 show the results of 


\begin{tabular}{|c|c|c|c|}
\hline \multirow{2}{*}{$\begin{array}{l}\text { TABLE } 1 \\
\text { Variable }\end{array}$} & \multicolumn{3}{|c|}{$\begin{array}{l}\text { Demographic and clinical characteristics of } \\
\text { parents }\end{array}$} \\
\hline & & Mother & Father \\
\hline \multicolumn{4}{|c|}{ General characteristics } \\
\hline Subjects $n$ & & 685 & 602 \\
\hline Age yrs & & $30.8 \pm 4.1$ & $32.9 \pm 4.4$ \\
\hline Height $\mathrm{cm}$ & & $169.9 \pm 7.0$ & $183.3 \pm 8.3$ \\
\hline Z-score & & $0(-3.34-2.98)$ & $0(-7.21-2.96)$ \\
\hline Weight kg & & $70.8 \pm 12.5$ & $84.6 \pm 11.4$ \\
\hline Z-score & & $0(-2.50-4.32)$ & $0(-2.42-4.87)$ \\
\hline FEF25-75\% & & $3.91 \pm 0.91$ & $4.97 \pm 1.21$ \\
\hline Z-score & & $0(-2.72-3.89)$ & $0(-2.46-4.31)$ \\
\hline $\mathrm{FEV}_{1} \mathrm{~L}$ & & $3.27 \pm 0.50$ & $4.38 \pm 0.69$ \\
\hline Z-score & & $0(-2.98-3.13)$ & $0(-3.11-3.08)$ \\
\hline FVC L & & $3.79 \pm 0.60$ & $5.23 \pm 0.83$ \\
\hline Z-score & & $0(-2.70-3.89)$ & $0(-3.49-2.90)$ \\
\hline FEF25-75\%/ & & $1.05 \pm 0.25$ & $0.96 \pm 0.25$ \\
\hline Z-score & & $0(-2.40-3.67)$ & $0(-2.30-3.56)$ \\
\hline \multicolumn{4}{|c|}{ Questionnaire data } \\
\hline History of a & thma/ bronchitis & 6.8 & 6.5 \\
\hline History of a & ergy & 42.9 & 41.5 \\
\hline \multicolumn{4}{|c|}{ Smoking status } \\
\hline Never & & 61.5 & 55.1 \\
\hline Ex-smok & & 28.3 & 27.7 \\
\hline Current s & noker & 10.2 & 17.2 \\
\hline \multicolumn{4}{|c|}{ Socioeconomic status } \\
\hline Low & & 4.1 & 4.7 \\
\hline Moderate & & 30.0 & 36.3 \\
\hline High & & 65.9 & 59.0 \\
\hline \multicolumn{4}{|l|}{ Ethnicity } \\
\hline Caucasia & & 81.1 & 83.6 \\
\hline Non-Cau & asian & 18.9 & 16.4 \\
\hline Exposure tc & pets & 43.1 & 43.8 \\
\hline
\end{tabular}

Data are presented as mean $\pm \mathrm{SD}$, mean (range) or \%, unless otherwise stated. FEF $25-75 \%$ : forced expiratory flow at $25-75 \%$ of forced vital capacity (FVC); FEV1: forced expiratory volume in $1 \mathrm{~s}$

the multiple linear regression models. After adjusting for age, gestational age and sex (model II) as well as exposure to pets, parental socioeconomic status, parental smoking status, and parental asthma and allergy status (model VI), the observed relationships remained statistically significant. The relationship between Rrs and FEF25-75\%/FVC was statistically significant in all multiple linear regression models. Adjusting for body size only partly explained the relationship between parental lung function and their children's lung function. The significance of the relationship between $\mathrm{Crs}$ and parental FVC $(\beta=0.02, p=0.075)$, and between Rrs and parental FEV1 $(\beta=-0.03, p=0.073)$ was reduced, and only showed a trend after adjusting for body size at the time of visit for lung function measurement (model III). The relationship between $\mathrm{Crs}_{\mathrm{rs}}$ and parental FVC disappeared after adjusting for length and weight at birth (model IV; $\beta=0.02, p=0.135$ ). Adjusting for weight and height of the parents (model V) did not change the observed results. To further investigate the role of infant body size, specific $C_{\mathrm{rs}}\left(C_{\mathrm{rs}}\right.$ per $\mathrm{kg}$ ) and specific $\operatorname{Rrs}(R \mathrm{rs}$ per $\mathrm{kg}$ ) were

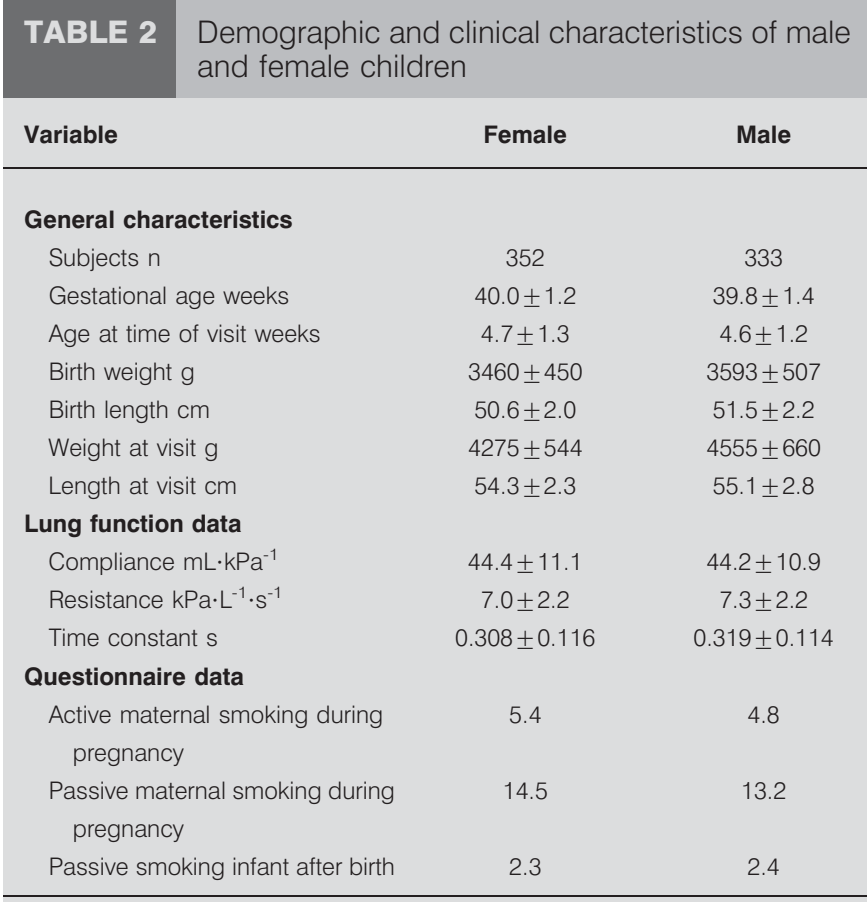

Data are presented as mean \pm SD or $\%$, unless otherwise stated.

used as dependent (outcome) variables in model VII. We found a significant relationship between infant specific $R$ rs and parental FEF25-75\%, FEV1 and FVC, and between infant specific Crs and parental FEF25-75\% and FEV1

Table 4 shows the results of the univariate linear regression analysis with maternal and paternal lung function variables as the independent variables, and their children's lung function variables as the dependent (outcome) variables (model I). For the mother-infant pairs, univariate linear regression analysis demonstrated a significant positive relationship between $C$ rs of the infant and $\mathrm{FEF} 25-75 \%$, FEV1 and FVC. Adjusting for body size and shared environmental factors (models II-VII) did not change the observed relationships. A significant positive relationship was also found between the respiratory time constant $\tau_{\mathrm{rs}}$ and maternal FEV1 and FVC. The relationship between $\tau$ rs and maternal FEV1 and FVC, however, disappeared after adjusting for length and weight at visit and at birth (models III and IV). Adjustments for age, gestational age and sex (model II), maternal weight and length (model V), and exposure to pets, maternal socioeconomic status, maternal smoking status, and maternal asthma and allergy status (model VI) did not change the observed results. No significant association was found between maternal lung function levels and Rrs, except after adjusting for maternal weight and length (model V), with a borderline significant relationship between $R$ rs and FEF25-75\%/ FVC $(\beta=-0.08, p=0.070)$ and after adjusting for exposure to pets, maternal socioeconomic status, maternal smoking status, and maternal asthma and allergy status (model VI), with a borderline significant relationship between Rrs and FEF $25-75 \%$ $(\beta=-0.03, p=0.054)$ and FEV1 $(\beta=-0.04, p=0.073)$. Specific Rrs was significantly associated with maternal FEV1 $(\beta=-0.071$, $\mathrm{p}=0.009)$. 
TABLE 3 The relationship between lung function of parents and their children

\begin{tabular}{|c|c|c|c|c|c|c|c|c|c|}
\hline \multirow{2}{*}{$\begin{array}{l}\text { Sum of paternal and } \\
\text { maternal lung function }\end{array}$} & \multicolumn{3}{|c|}{ Ln Crs mL.kPa ${ }^{-1}$} & \multicolumn{3}{|c|}{ Ln Rrs $\mathrm{kPa} \cdot \mathrm{L}^{-1} \cdot \mathrm{s}^{-1}$} & \multicolumn{3}{|c|}{ Ln trs $s$} \\
\hline & $\beta$ coefficient $(95 \% \mathrm{Cl})$ & $\mathbf{R}^{2}$ & $\mathrm{p}$-value & $\beta$ coefficient $(95 \% \mathrm{Cl})$ & $\mathbf{R}^{2}$ & p-value & $\beta$ coefficient $(95 \% \mathrm{Cl})$ & $\mathbf{R}^{2}$ & p-value \\
\hline FEF $25-75 \% L \cdot s^{-1}$ & $0.019(0.005-0.032)$ & 0.013 & 0.007 & $-0.022(-0.038--0.006)$ & 0.014 & 0.006 & $-0.003(-0.022-0.016)$ & 0.0001 & 0.749 \\
\hline FEV1 L & $0.045(0.022-0.068)$ & 0.027 & $<0.001$ & $-0.034(-0.061--0.011)$ & 0.011 & 0.013 & $0.011(-0.021-0.043)$ & 0.001 & 0.492 \\
\hline FVC L & $0.032(0.013-0.051)$ & 0.020 & 0.001 & $-0.012(-0.035-0.010)$ & 0.002 & 0.278 & $0.020(-0.006-0.046)$ & 0.004 & 0.140 \\
\hline
\end{tabular}

The data show unadjusted linear regression coefficients. Crs: compliance of the respiratory system; Rrs: resistance of the respiratory system; $\tau$ rs: time constant of the respiratory system; FEF25-75\%: forced expiratory flow at $25-75 \%$ of forced vital capacity (FVC); FEV1: forced expiratory volume in $1 \mathrm{~s}$.

For the father-infant pairs (table 4), there were no significant associations between paternal lung function variables, and $\mathrm{Crs}$ and specific $C_{r s}$, except after adjusting for age, gestational age and sex (model II), with a significant positive relationship between $C_{\text {rs }}$ and FEV1 $(\beta=0.03, p=0.026)$ and FVC $(\beta=0.03$, $\mathrm{p}=0.033)$. For Rrs, FEF25-75\% and FEV1 showed a significant negative relationship that did not change after adjusting for body size and shared environmental factors (models II-VI), except for the relationship between $R$ rs and paternal FEV1 $(\beta=-0.03, p=0.063)$ only showing a trend after adjusting for infant body size at the time of visit for lung function measurement (model III). No significant association was found between paternal lung function levels and specific $R$ rs and $\tau$ rs.

\section{DISCUSSION}

In this study, we found that parental lung function is a determinant of their children's lung function early in life. This relationship could, in part, be explained by familial aggregation of body size. After adjusting for body size of parents and infants the majority of the significant relationships between parental and infant lung function remained significant. This relationship could not be explained by other factors, such as age, sex, medical history of the parents, or shared environmental factors during pregnancy and shortly after birth. This suggests genetic mechanisms in the familial aggregation of lung function, which are already detectable very early in life. To our knowledge, this is the first study investigating the influence of parental lung function parameters in the prediction of their children's lung function very early in life.

Some methodological aspects need to be considered. The group of infants selected for this study was a sample from all infants participating in the WHISTLER study. Selection was based on whether the parents participated in the Utrecht Health Project, as this study provided the parental data. Although parental data

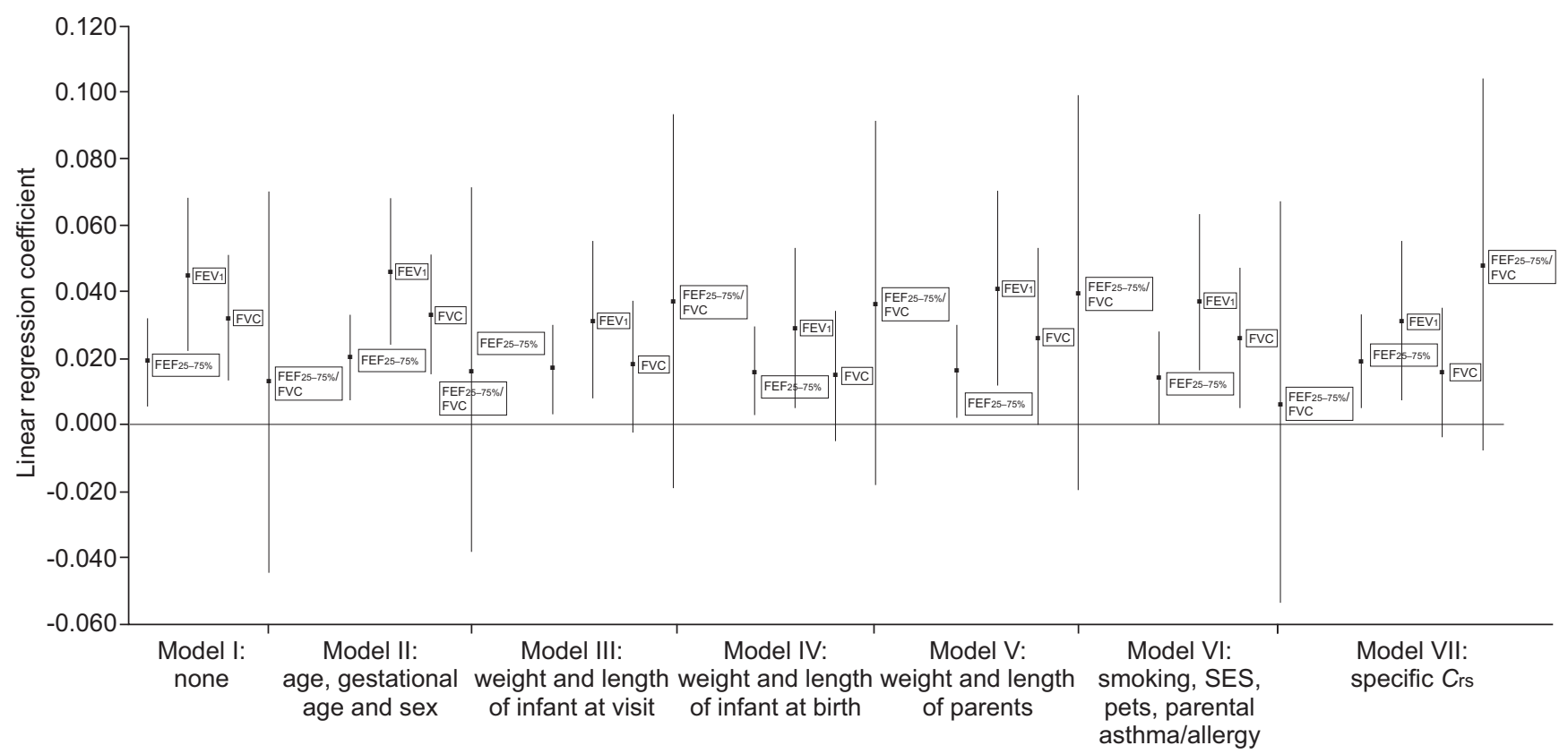

FIGURE 2. The relationship between parental lung function (forced expiratory flow at 25-75\% forced vital capacity (FEF25-75\%); forced expiratory volume in $1 \mathrm{~s}$ (FEV1); forced vital capacity (FVC); ratio FEF25-75\%/FVC) and compliance (Crs) of their children. Unadjusted and adjusted linear regression coefficients are shown and whiskers represent 95\% confidence interval. SES: socioeconomic status. 


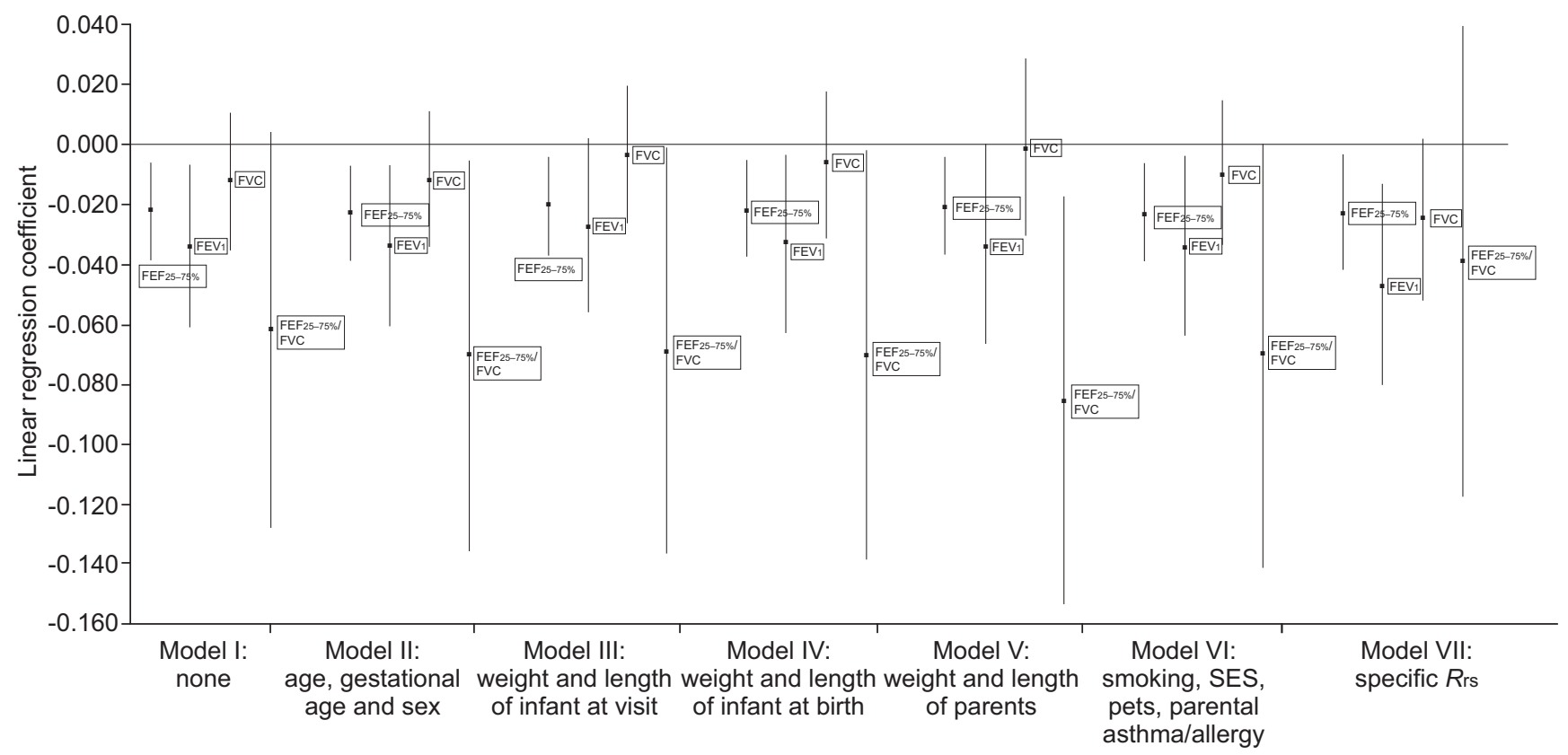

FIGURE 3. The relationship between parental lung function (forced expiratory flow at $25-75 \%$ forced vital capacity (FEF25-75\%); forced expiratory volume in $1 \mathrm{~s}$ (FEV1); forced vital capacity (FVC); ratio FEF25-75\%/FVC) and resistance (Rrs) of their children. Unadjusted and adjusted linear regression coefficients are shown and whiskers represent 95\% confidence interval. SES: socioeconomic status.

could not be compared between included and excluded infants, the baseline characteristics and lung function variables of the excluded infants were similar to those of the infants included in this study (data not shown). Therefore, it is unlikely that selective participation has affected our results. The SOT is a suitable and noninvasive method to measure lung function, but the individual assessment, especially the reliability of the measurements, needs to be critically evaluated [16, 20]. Difficulties in the underlying assumptions of complete relaxation, equilibration of pressures and a single time constant for the respiratory system can influence the validity and accuracy of measurements. In order to ensure that only technically satisfactory data were analysed and reported, measurements were performed by trained personnel according to the criteria of the ERS/ATS Task Force [17].

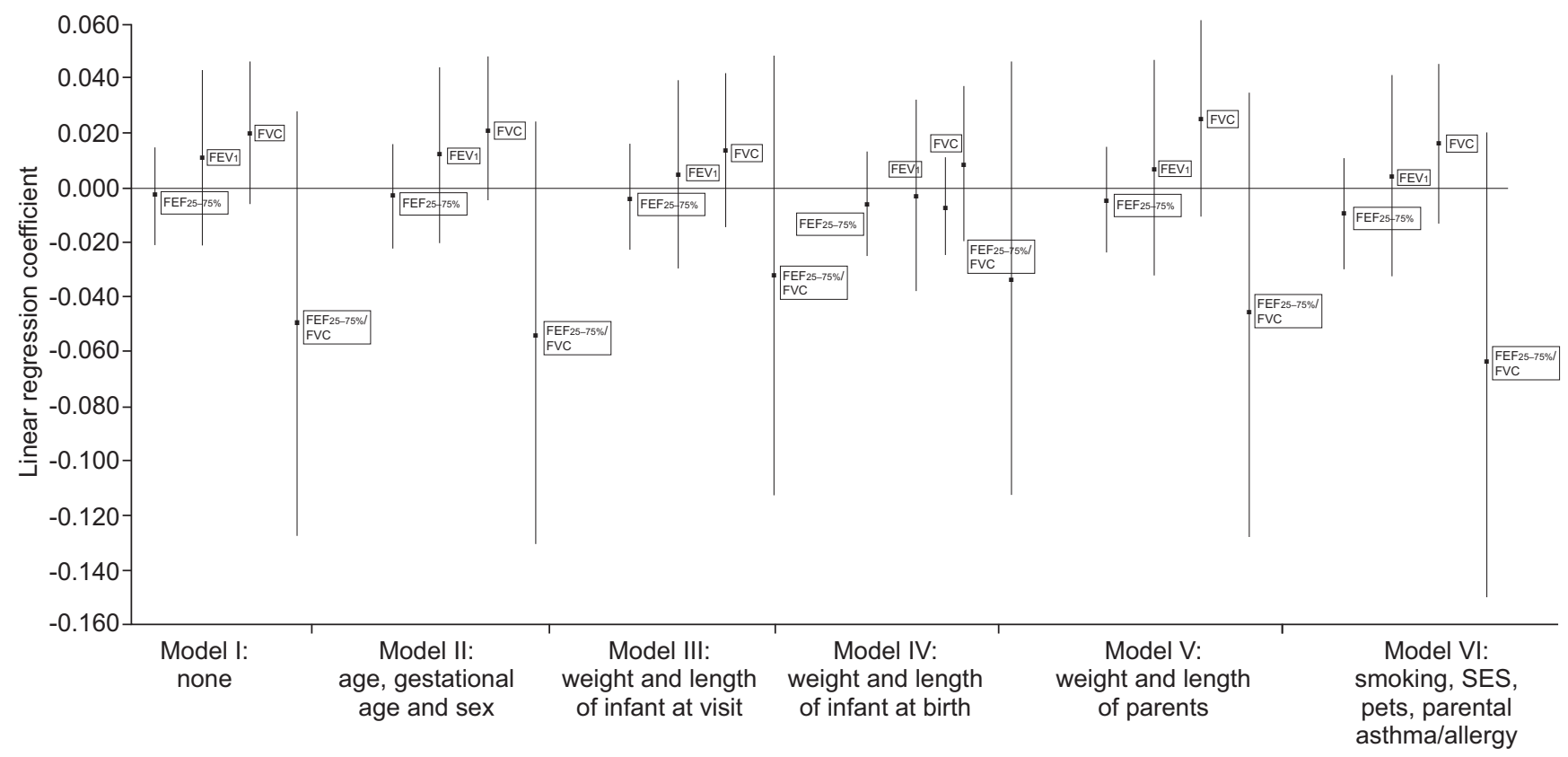

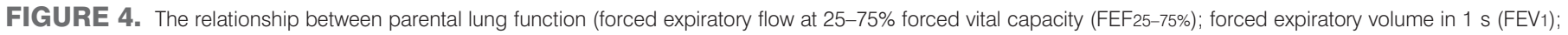

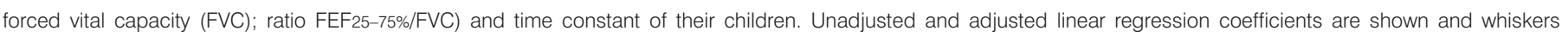
represent $95 \%$ confidence interval. SES: socioeconomic status. 
TABLE 4 The relationship between lung function of the mother and father and their children

\begin{tabular}{|c|c|c|c|c|c|c|c|c|c|}
\hline & \multicolumn{3}{|c|}{ Ln Crs $\mathrm{mL} \cdot \mathrm{kPa}^{-1}$} & \multicolumn{3}{|c|}{ Ln Rrs $\mathrm{kPa} \cdot \mathrm{L}^{-1} \cdot \mathrm{s}^{-1}$} & \multicolumn{3}{|c|}{ Ln trs $\mathbf{s}$} \\
\hline & $\beta$ coefficient $(95 \% \mathrm{Cl})$ & $\mathbf{R}^{2}$ & $p$-value & $\beta$ coefficient $(95 \% \mathrm{Cl})$ & $\mathbf{R}^{2}$ & $p$-value & $\beta$ coefficient $(95 \% \mathrm{Cl})$ & $\mathbf{R}^{2}$ & p-value \\
\hline \multicolumn{10}{|c|}{ FEF $25-75 \% L \cdot \mathrm{s}^{-1}$} \\
\hline Mother & $0.033(0.012-0.054)$ & 0.014 & 0.002 & $-0.018(-0.042-0.005)$ & 0.003 & 0.130 & $0.014(-0.014-0.043)$ & 0.001 & 0.319 \\
\hline Father & $0.009(-0.008-0.025)$ & 0.002 & 0.299 & $-0.024(-0.043--0.005)$ & 0.010 & 0.015 & $-0.015(-0.038-0.008)$ & 0.003 & 0.191 \\
\hline Father & $0.026(-0.003-0.055)$ & 0.005 & 0.075 & $-0.045(-0.078--0.011)$ & 0.011 & 0.010 & $-0.018(-0.058-0.021)$ & 0.001 & 0.368 \\
\hline \multicolumn{10}{|l|}{ FVC L } \\
\hline Mother & $0.062(0.030-0.093)$ & 0.021 & 0.001 & $-0.009(-0.045-0.027)$ & 0.0001 & 0.627 & $0.053(0.010-0.096)$ & 0.008 & 0.016 \\
\hline Father & $0.020(-0.004-0.044)$ & 0.004 & 0.111 & $-0.022(-0.050-0.005)$ & 0.004 & 0.114 & $-0.003(-0.036-0.030)$ & 0.0001 & 0.862 \\
\hline \multicolumn{10}{|c|}{ FEF25-75\%/FVC } \\
\hline Mother & $0.012(-0.065-0.089)$ & 0.0001 & 0.757 & $-0.052(-0.139-0.035)$ & 0.002 & 0.244 & $-0.040(-0.144-0.065)$ & 0.001 & 0.455 \\
\hline
\end{tabular}

The data show unadjusted linear regression coefficients. Crs: compliance of the respiratory system; Rrs: resistance of the respiratory system; trs: time constant of the respiratory system; FEF25-75\%: forced expiratory flow at 25-75\% of forced vital capacity (FVC); FEV1: forced expiratory volume in $1 \mathrm{~s}$.

Although we are comparing lung function variables assessed by two different lung function techniques, it seems reasonable to assume that genetically or environmentally mediated determinants of lung function, including the size of the airways and lungs, and the lung elastic recoil and resistance properties, will be detected by both techniques. The inverse relationship between the sum of parental FEV1, FEF25-75\% and FEF25-75\%/FVC, and their children's Rrs is understandable as all parameters are a reflection of airway calibre (e.g. decrease of FEV1 and FEF25-75\% with higher resistance). In contrast, no significant relationship was found between the parental lung volume parameter FVC and Rrs. For the children's Crs, a significant positive relationship was found with parental FEV1, FEF25-75\% and FVC. Crs reflects composite elastic properties of the infant total respiratory system, which apparently correlates with both airway calibre and lung volume characteristics in parents. As proposed by TAGER et al. [19], FEF25-75\%/FVC is a measure of airway size relative to lung size (relative airway size) and, in contrast to $R$ rs, $C$ rs was not related to this variable. The time constant $\tau_{\mathrm{rs}}$ is the time necessary for $\sim 63 \%$ of the lung to empty and equal the product of Crs and Rrs. Parental lung function variables were negatively associated with $R$ rs and positively associated with $C$ rs, which explains why no significant relationship was found between parental lung function variables and $\tau$ rs. Maternal lung function, however, showed a significant relationship with their children's $\tau \mathrm{rs}$, most probably due to the dominant maternal effect on Crs.

Lung function is known to aggregate in families. A familial effect on measurements of FEF50, FEF25-75\%, FEV1, FVC and FEF25-75\%/FVC at older ages has been shown [4-6, 21], but there is conflicting evidence as to whether this is genetically determined or due to shared environments. In this study, we found a significant relationship between several parental lung function variables and $R$ rs and $C r$ of their children early in life. A genetic basis for the findings in our study is supported by the fact that after adjusting for shared environmental factors during pregnancy and shortly after birth, such as smoking status of the parents, exposure to pets, parental asthma and allergy status, and socioeconomic status, the observed relationships remained significant.

To what extent familial aggregation of lung function is primarily a reflection of familial aggregation of body size has been a source of controversy. It is generally agreed that height aggregates in families and pulmonary function measurements are dependent on height [22]. LEBOWITz et al. [23] presented strong familial aggregation for FVC, FEV1 and maximum expiratory flow rate at $50 \%$ of vital capacity, but these relationships disappeared after controlling for body size. In contrast, KAUFFMANN et al. [5] found that adjustment for body size did not affect the magnitude of the parent-child correlations for FEF25-75\%, FEV1 or FVC. In our study, we found that familial aggregation of weight and length was, in part, an explanatory variable for the observed relationship between parental lung function variables and lung function of their children.

It is interesting to note that other studies found a greater correlation in FEV1 and other lung function variables between mothers and their children compared with fathers and their children $[5,9]$. In this study, we also found differences in the relationship between maternal and paternal lung function levels, and lung function level of their newborn infant. Sex of the parent modifies the relationship between parental lung function and lung function of their children with a more dominant effect of the mother's lung function on their children's $C_{r s}$ and $\tau_{r s}$, and a more dominant effect of the father's lung function on their children's Rrs. There are some interpretations found in the literature. These include exclusive exposure to maternal genetic or environmental factors during pregnancy, differences in shared post-natal environmental exposures, hormonal differences and genetic imprinting, where the genetic factors exert their effects dependent on whether they were inherited from the father or mother [24]. In addition, HOLBERG et al. [9] observed a significant maternal-offspring correlation in 
FEV1 in asthmatic families and suggested a connection with the maternal environment in utero; more specifically, while both parents may contribute to the susceptibility of atopic disease, additional environmental effects with a maternal influence may influence the expression of the genetic factors and subsequently affect lung function. In our study, a positive maternal or paternal history of asthma or allergy did not change the observed associations between parental lung function and lung function of their offspring.

In conclusion, we demonstrated, as part of a large prospective, population-based birth cohort study on determinants of wheezing illnesses (WHISTLER), that parental lung function levels are predictors of respiratory mechanics of their newborn infants, which could be explained, in part, by familial aggregation of body size. This suggests genetic mechanisms in familial aggregation of lung function, which are already detectable very early in life. Although currently speculative, the findings of this study may contribute to the understanding of the genetic mechanism of lung function and subsequently the development and progression of lung disease in childhood and beyond.

\section{SUPPORT STATEMENT}

This study was funded by the Health Research and Development Council of the Netherlands (grant number 2001-1-1322), and by an unrestricted grant from GlaxoSmithKline (Zeist, the Netherlands). Neither of these funding sources had any role in or influence on the study execution.

\section{STATEMENT OF INTEREST}

A statement of interest for the present study can be found at www.erj. ersjournals.com/site/misc/statements.xhtml

\section{REFERENCES}

1 Young S, Arnott J, O'Keeffe PT, et al. The association between early life lung function and wheezing during the first 2 yrs of life. Eur Respir J 2000; 15: 151-157.

2 Celedon JC, Wright RJ, Litonjua AA, et al. Day care attendance in early life, maternal history of asthma, and asthma at the age of 6 years. Am J Respir Crit Care Med 2003; 167: 1239-1243.

3 Moffatt MF, Cookson WO. The genetics of asthma. Maternal effects in atopic disease. Clin Exp Allergy 1998; 28: Suppl. 1, 56-61.

4 Coultas DB, Hanis CL, Howard CA, et al. Heritability of ventilatory function in smoking and nonsmoking New Mexico Hispanics. Am Rev Respir Dis 1991; 144: 770-775.

5 Kauffmann F, Tager IB, Munoz A, et al. Familial factors related to lung function in children aged 6-10 years. Results from the PAARC epidemiologic study. Am J Epidemiol 1989; 129: 1289-1299.

6 Lewitter FI, Tager IB, McGue M, et al. Genetic and environmental determinants of level of pulmonary function. Am J Epidemiol 1984; 120: 518-530.
7 Chen Y, Horne SL, Rennie DC, et al. Segregation analysis of two lung function indices in a random sample of young families: the Humboldt Family Study. Genet Epidemiol 1996; 13: 35-47.

8 Givelber RJ, Couropmitree NN, Gottlieb DJ, et al. Segregation analysis of pulmonary function among families in the Framingham Study. Am J Respir Crit Care Med 1998; 157: 14451451.

9 Holberg CJ, Morgan WJ, Wright AL, et al. Differences in familial segregation of FEV1 between asthmatic and nonasthmatic families. Role of a maternal component. Am J Respir Crit Care Med 1998; 158: 162-169.

10 Redline S, Tishler PV, Lewitter FI, et al. Assessment of genetic and nongenetic influences on pulmonary function. A twin study. Am Rev Respir Dis 1987; 135: 217-222.

11 Wilk JB, Chen TH, Gottlieb DJ, et al. A genome-wide association study of pulmonary function measures in the Framingham Heart Study. PLoS Genet 2009; 5: e1000429.

12 Palmer LJ, Knuiman MW, Divitini ML, et al. Familial aggregation and heritability of adult lung function: results from the Busselton Health Study. Eur Respir J 2001; 17: 696-702.

13 Chen Y, Rennie DC, Lockinger LA, et al. Major genetic effect on forced vital capacity: the Humboldt Family Study. Genet Epidemiol 1997; 14: 63-76.

14 Katier N, Uiterwaal CSPM, de Jong BM, et al. The Wheezing Illnesses Study Leidsche Rijn (WHISTLER): rationale and design. Eur J Epidemiol 2004; 19: 895-903.

15 Grobbee DE, Hoes AW, Verheij TJ, et al. The Utrecht Health Project: optimization of routine healthcare data for research. Eur J Epidemiol 2005; 20: 285-287.

16 Fletcher ME, Baraldi B, Steinbrugger B. Passive respiratory mechanics. In: Stock J, Sly PD, Tepper RS, et al., eds. Infant respiratory function testing. New York, Wiley-Liss, 1996; pp. 283-327.

17 Gappa M, Colin AA, Goetz I, et al. Passive respiratory mechanics: the occlusion techniques. Eur Respir J 2001; 17: 141-148.

18 Standardization of spirometry, 1994 update. American Thoracic Society. Am J Respir Crit Care Med 1995; 152: 1107-1136.

19 Tager IB, Weiss ST, Munoz A, et al. Determinants of response to eucapneic hyperventilation with cold air in a population-based study. Am Rev Respir Dis 1986; 134: 502-508.

20 Katier N, Uiterwaal CS, de Jong BM, et al. Feasibility and variability of neonatal and infant lung function measurement using the single occlusion technique. Chest 2005; 128: 1822-1829.

21 DeMeo DL, Carey VJ, Chapman HA, et al. Familial aggregation of FEF25-75 and FEF25-75/FVC in families with severe, early onset COPD. Thorax 2004; 59: 396-400.

$22 \mathrm{Xu}$ J, Bleecker ER, Jongepier H, et al. Major recessive gene(s) with considerable residual polygenic effect regulating adult height: confirmation of genomewide scan results for chromosomes 6, 9, and 12. Am J Hum Genet 2002; 71: 646-650.

23 Lebowitz MD, Knudson RJ, Burrows B. Family aggregation of pulmonary function measurements. Am Rev Respir Dis 1984; 129: 8-11.

24 Raby BA, Van Steen K, Celedon JC, et al. Paternal history of asthma and airway responsiveness in children with asthma. Am J Respir Crit Care Med 2005; 172: 552-558. 